\title{
Duration and level of transgene expression after gene electrotransfer to skin in mice
}

\author{
A Gothelf ${ }^{1}, \mathrm{~J} \mathrm{Eriksen}^{1}, \mathrm{P}$ Hojman ${ }^{1,2}$ and J Gehl ${ }^{1}$ \\ ${ }^{1}$ Department of Oncology, Center for Experimental Drug and Gene Electrotransfer, Copenhagen University Hospital Herlev, \\ Herlev, Denmark and ${ }^{2}$ Centre of Inflammation and Metabolism, Department of Infectious Diseases, Copenhagen University Hospital, \\ Copenhagen, Denmark
}

In development of novel vaccines, attention is drawn to DNA vaccinations. They are heat stable and can be easily produced. Gene electrotransfer is a simple and nonviral means of transferring DNA to cells and tissues and is attracting increasing interest. One very interesting perspective with gene electrotransfer is that choice of tissue can determine the duration of transgene expression. With gene electrotransfer to muscle, long-term expression, that is beyond 1 year, can be obtained, whereas gene electrotransfer to skin gives short-term expression, which is desirable in, for example, DNA vaccinations. Level and duration of transgene expression after gene electrotransfer to skin is essential and here we present data from two independent quantitative studies. Using in vivo bioimaging of a far-red fluorescent molecule, Katushka, allowing for continuous monitoring of local gene expression, compared with measurements of a systemic transgene, that is, serum erythropoietin (EPO) after gene electrotransfer with EPO to skin, we found a significant increase in transgene expression $(\mathrm{P}<0.01)$ with a peak 9 days (Katushka) and 14 days (EPO) after transfection. Duration of expression could be 3-4 weeks, which is a suitable time frame for vaccinations and is applicable, for example, in gene therapy for wound healing or treatment of cancer.

Gene Therapy (2010) 17, 839-845; doi:10.1038/gt.2010.35; published online 8 April 2010

Keywords: electroporation; gene electrotransfer; Katushka; erythropoietin; vaccination

\section{Introduction}

Gene electrotransfer is a nonviral means of transferring genes into cells and tissues and is regarded as an effective and safe procedure. ${ }^{1-3}$ A vast number of studies have encompassed gene electrotransfer to muscles, ${ }^{4-8}$ but the technique is also efficient in, for example, cornea, ${ }^{9}$ lungs, ${ }^{10}$ liver ${ }^{11,12}$ kidney, ${ }^{13}$ bladder, ${ }^{14}$ testis, ${ }^{15}$ skin $^{16,17}$ and tumor. ${ }^{18-20}$

One very interesting perspective with gene electrotransfer is that the choice of tissue can determine the duration of expression of the transgene. Gene transfection to muscle can give long-term expression lasting up to or beyond 1 year, $7,8,21$ whereas gene transfer to skin has the advantage of easy accessibility but can in comparison with muscle only give short-term expression. ${ }^{22,23}$ This is desirable in DNA vaccinations, where a long-term expression is not necessary.

In this context, increased attention is drawn at gene electrotransfer to skin. Skin contains antigen-presenting cells (Langerhans cells, dendritic cells), which are part of the immune surveillance system and is thus able to gain a response after vaccinations. Studies with DNA vaccinations in animal models have shown promising results in infectious diseases such as hepatitis $\mathrm{B}^{24-27} \mathrm{HIV}^{28}$

Correspondence: Dr J Gehl, Department of Oncology, Copenhagen University Hospital Herlev, 75 Herlev Ringvej, Herlev DK-2730, Denmark.

E-mail: juge@heh.regionh.dk

Received 2 October 2009; revised 14 February 2010; accepted 17 February 2010; published online 8 April 2010 malaria $^{29}$ and smallpox. ${ }^{30}$ Vaccination studies using intradermal electroporation in mice with DNA coding for prostate-specific antigen (PSA) gave increased level of PSA-specific T cells ${ }^{31,32}$ and a Phase I/II clinical trial (NCT00859729) is currently running.

Besides vaccinations, skin has the potential of creating a systemic response to gene electrotransfer. We have previously shown that gene electrotransfer with erythropoietin (EPO) to murine skin was able to achieve significant and relevant increase in hemoglobin and serum EPO compared to controls (Gothelf et al., accepted for publication $\left.{ }^{33}\right)$. We found a statistically significant increase in serum EPO $24 \mathrm{~h}$ after the gene electrotransfer procedure, and this increase remained significant until a peak was reached after 2 weeks.

In gene electrotransfer to skin, it is imperative to investigate the duration and the level of expression after the transfection, not only for vaccination purposes but also for transfection with other relevant compounds. Previous preclinical studies have primarily used luciferase ${ }^{17,23,32,34-36}$ and have used either in vitro measurement of luciferase activity in tissue homogenates or in vivo bioluminescence scans. However some drawbacks exist regarding this construct; it is known for displaying large variations, often of several $\operatorname{logs},{ }^{17}$ and thus the in vitro method warrants a large number of animals or samples to be processed.

Continuous monitoring of gene expression, which is possible with bioluminescence scans of luciferase or in vivo bioimaging of fluorescent molecules, not only reduces the number of animals used in experiments but also gets more reliable results as each animal is its own 
control. The advantage of using fluorescent molecules compared to luciferase is that no substrate is needed. In the case of luciferase, an injection of luciferin is needed, often injected intraperitoneally, to get the enzyme to react.

Until recently, in vivo bioimaging of skin after gene electrotransfer has been limited to green fluorescent protein and red fluorescent protein. Unfortunately green fluorescent protein may not be the optimal choice for evaluation of gene electrotransfer to skin due to autofluorescence from the skin itself. ${ }^{17,37}$

A new fluorescent marker molecule in the far-red area, Katushka, from the sea anemone Entacmaea quadricolor ${ }^{38}$ has proven to be very useful for in vivo imaging after gene electrotransfer to muscle ${ }^{39}$ and has a more intense signal than red fluorescent protein. With this new compound, it is now possible to investigate the duration and level of expression after gene electrotransfer to skin using continuous monitoring and in vivo bioimaging with time domain function. Time domain imaging allows quantitative analysis of the fluorescent marker due to precise determination of spatial and temporal distribution. ${ }^{39}$

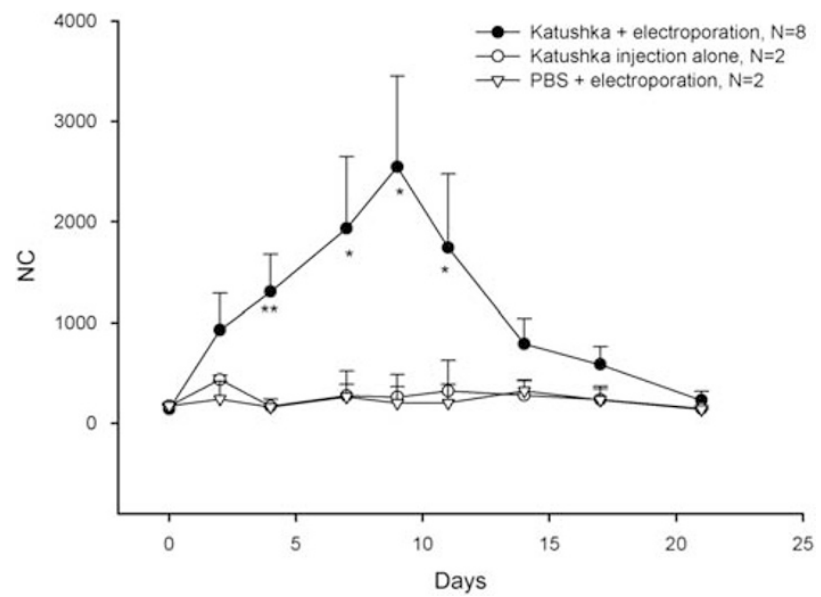

Figure 1 Level of intensity in normalized counts (NC) after gene electrotransfer with Katushka to mouse skin. The mean intensity increased after 2 days and was after 4 days statistically significant from controls $(P<0.01)$. After 9 days a peak was reached, the curve declined and the level of intensity was similar to the controls after 3 weeks. The depicted $P$-values were based on Student's $t$-test comparing Katushka + electroporation with the PBS control. Similar $P$-values were obtained when Katushka + electroporation was compared with Katushka injection alone. The reported intensities are mean values; error bars represent standard deviations. ${ }^{*} P<0.05$, ${ }^{* *} P<0.01$.
We therefore conducted a gene electrotransfer study to skin with a plasmid coding for Katushka and compared it to data from gene electrotransfer with EPO.

In addition, a study with consecutive in vivo bioluminescence scans to investigate the duration of expression after gene electrotransfer with luciferase to skin was performed.

Using these independent techniques, we have visualized local gene expression with continuous monitoring and measured serum levels of a systemic protein, and thus investigated the level and duration of expression of three different transgenes after gene electrotransfer to skin.

\section{Results}

In vivo bioimaging of Katushka after gene electrotransfer to skin: duration of expression

Two days after the gene electrotransfer procedure an increase in peak intensity was observed (mean 929 normalized counts (NC); Figures 1 and 2) and the difference between the transfected mice and the controls was statistically significant 4 days after the transfection, with mean $1303 \mathrm{NC}$ opposed to Katushka injection alone (mean $171 \mathrm{NC}, P<0.01$ ) and phosphate-buffered saline (PBS)+electroporation (mean $161 \mathrm{NC}, P<0.01$ ). The intensity peaked 9 days after the transfection (mean 2545 NC) and was significantly increased compared to Katushka injection alone (mean $262 \mathrm{NC}, P<0.05$ ) and PBS injection with electroporation (mean 203 NC, $P<0.05)$. The intensity was normalized after 3 weeks (mean $231 \mathrm{NC}$ ). Lifetime analysis of the area with high intensity showed a lifetime of 2.1 consistent with the fluorescent lifetime of Katushka (Figure 3). ${ }^{39}$ The study was performed twice and reached the same conclusion.

\section{Comparison of duration and level of expression of Katushka with EPO data}

In Figure 4 the duration and level of expression are depicted for gene electrotransfer to skin with Katushka and EPO. The expression of Katushka peaks 9 days after the transfection, whereas EPO expression peaks after 14 days.

The level of intensity after gene electrotransfer with Katushka was normalized after 3 weeks, and serum EPO levels after gene electrotransfer with EPO to skin were declining after the peak to a near-baseline value after 4 weeks. Serum EPO was fully normalized after 8 weeks (data not shown).

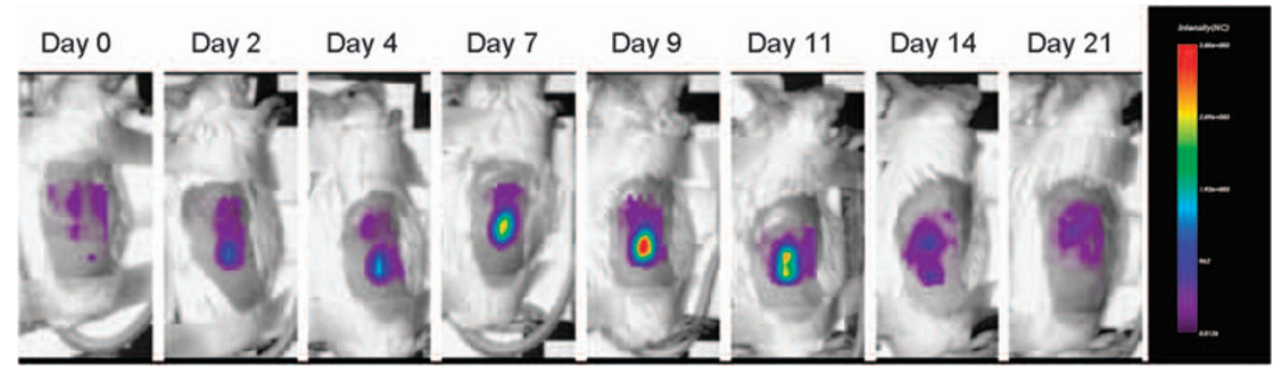

Figure 2 In vivo bioimaging of skin after gene electrotransfer with Katushka to skin. With this modality, it is possible to perform consecutive scans and thus continuous monitoring of the same animal. In this study, we have scanned the animals at different time points and in this figure it is possible to visualize the peak in expression observed at day 9. 

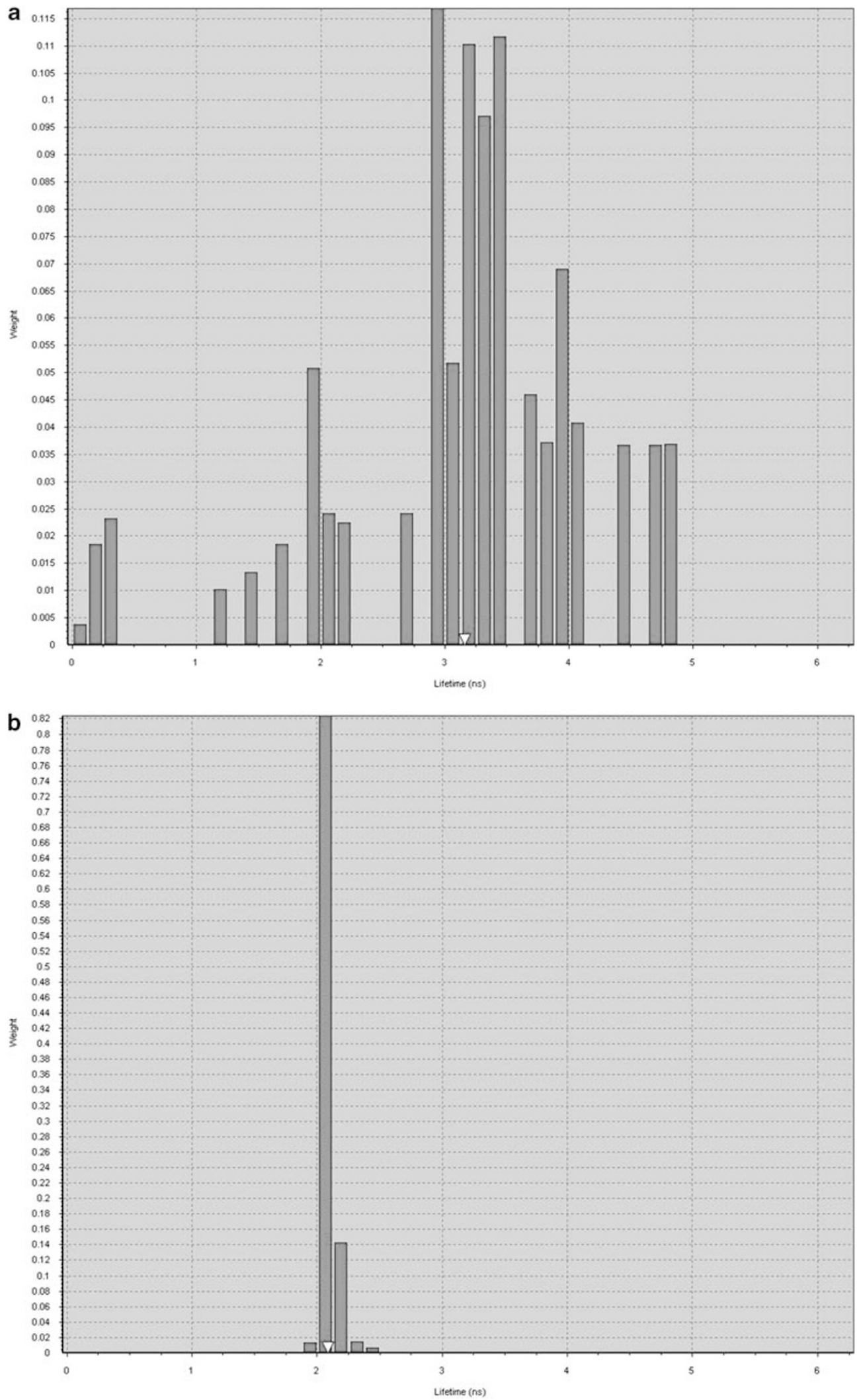

Figure 3 Comparison of lifetime histograms between day 0 and 9. In the software Optiview, it is possible to detect the fluorescent lifetime of each scanned point. The lifetime is characteristic for each fluorochrome and indicates the time in nanoseconds (ns) the fluorescent molecule stays in its excited state before emitting a photon. Before gene transfection with Katushka to skin, the scanned area has no particular lifetime (a). After gene electrotransfer with Katushka to skin, the lifetime is narrowed around $2.1 \mathrm{~ns}$ if the area expresses Katushka (b). 


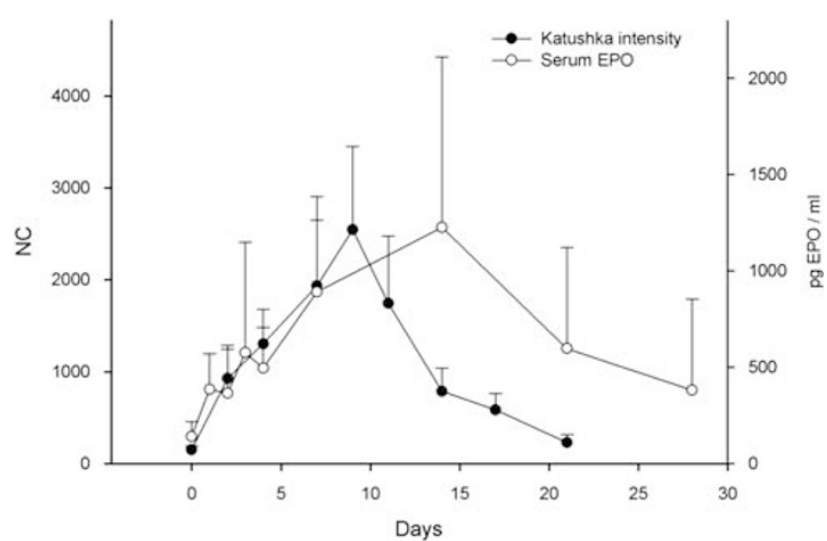

Figure 4 Comparison of gene electrotransfer to skin with Katushka with EPO in terms of duration and level of expression. With Katushka a peak in expression (in NC) is reached after 9 days, whereas serum EPO (in pg EPO per ml) seems to peak after 14 days.

\section{Investigation of the optimal time point for bioluminescence scanning after i.p. injection of luciferin}

Seven mice received gene electrotransfer with luciferase to skin and were scanned for bioluminescence $48 \mathrm{~h}$ after the transfection procedure (Figure 5). Three minutes after the injection of luciferin the intensity in NC has increased significantly from mean 10 to mean $27 \mathrm{NC}(P<0.01)$. After $12 \mathrm{~min}$ the intensity has reached a plateau on a logarithmic scale. We thus concluded that scanning for bioluminescence $20 \mathrm{~min}$ after intraperitoneal (i.p.) injection of luciferin would be representative of the degree of transfection. The controls remained consistently at baseline intensity.

\section{Expression of luciferase over time after gene electrotransfer to skin}

Twenty-four hours after the transfection, the mean intensity, in the luciferase transfected group, was increased from 15.6 to $174.4 \mathrm{NC}(P<0.01$, Figure 6). After $48 \mathrm{~h}$ a peak of intensity was reached (mean $434.1 \mathrm{NC}$, $P<0.01)$. The intensity declined hereafter and was near the baseline level 17 days after the transfection. The controls had consistently intensity levels from 15 to $20 \mathrm{NC}$.

\section{Discussion}

Skin is a good target for gene therapy due to its accessibility and the easiness in which it can be evaluated. It is capable of expressing genes transfected by electroporation, locally as is the case with Katushka and luciferase, but also systemically, as we have shown with EPO. ${ }^{33}$ Compared to gene electrotransfer to muscle, short-term expression must be expected. Muscle cells do not (or seldom) divide, whereas cells in the skin (epidermal and dermal cells) are subject to constant mitotic activity, cell division, cell death and in the case of keratinocytes, desquamation from the surface.

Then why bother to transfect genes into skin? Would it not be better to use muscles instead? In many cases this would be right; the muscle cell can easily function as a 'protein-factory' and compared to skin much less DNA is

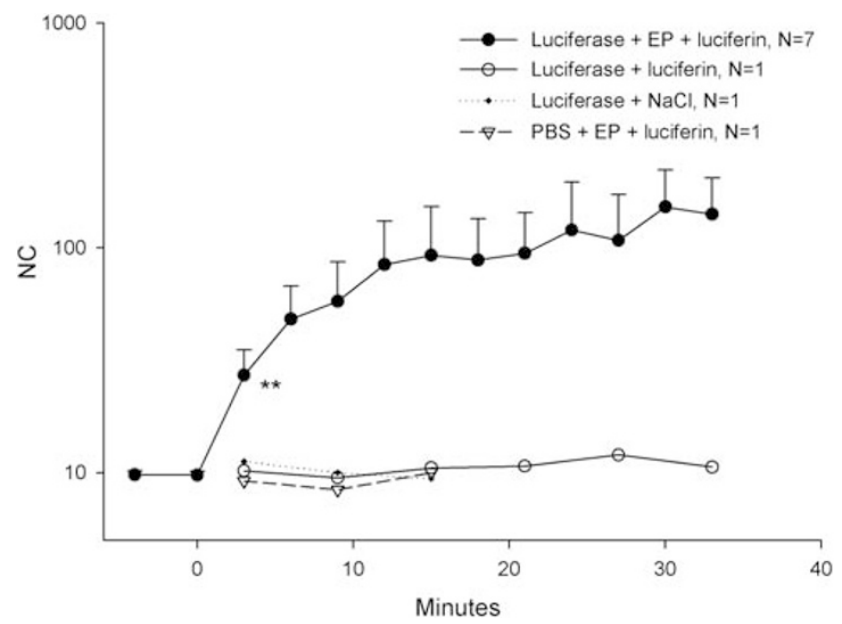

Figure 5 Investigation of optimal time for bioluminescence scanning after i.p. injection of luciferin. Mice were transfected with luciferase to skin and $48 \mathrm{~h}$ later they were scanned for bioluminescence. They received $3 \mathrm{mg}$ luciferin $\left(10 \mathrm{mg} \mathrm{ml}^{-1}\right)$ i.p. and were scanned consecutively. Three minutes after the luciferin injection, a statistical significant increase $(P<0.01)$ in intensity was observed and after $12 \mathrm{~min}$, a plateau was reached on a logarithmic scale. Previous studies have shown that merely the combination of luciferase plasmid injection, electroporation and luciferin injection before scans yielded response, why we chose to use as few controls as possible. EP electroporation, ${ }^{* *} P<0.01$.

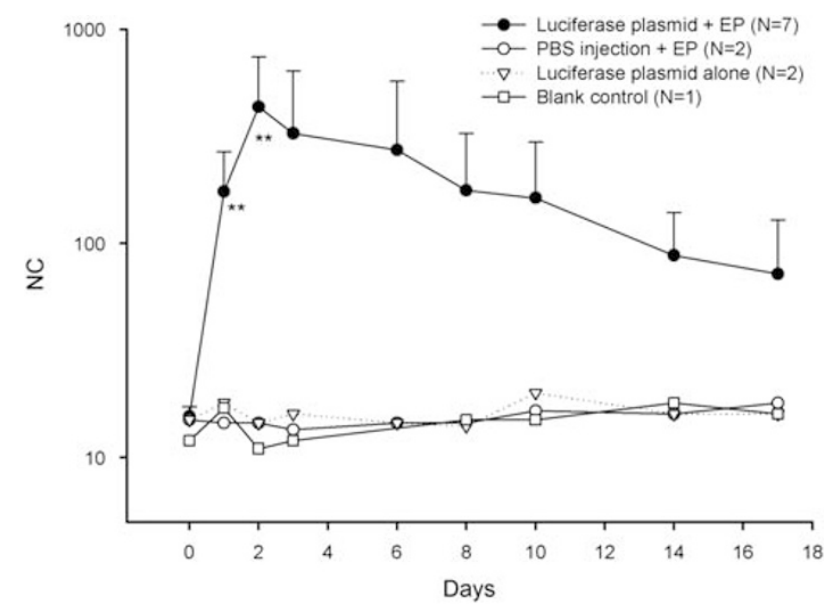

Figure 6 Duration of expression of luciferase after gene electrotransfer to skin. Mice were transfected with luciferase and scanned on different time points after i.p. administration of $3 \mathrm{mg}$ luciferin. Bioluminescence was measured in normalized counts (NC). After $24 \mathrm{~h}$ there was an increase in intensity from mean 15.6 to mean 174.4 NC. The intensity peaked at $48 \mathrm{~h}$ and declined hereafter slowly toward the baseline intensity level. The controls had no increase in intensity but remained consistently at the baseline level. EP electroporation, ${ }^{* *} P<0.01$.

needed to give the same response. ${ }^{7,39}$ However, in other cases a long-term expression is not warranted. In DNA vaccinations, the transfection only needs to be efficient long enough for the immune system to respond and in, for example, wound healing there is no need for extra production of growth factors once the wound has closed. ${ }^{40}$ Furthermore, skin contains antigen-presenting cells and would with optimal conditions probably be more efficient in creating an antigen response after gene electrotransfer with DNA vaccines than muscle. ${ }^{29}$ 
If we want gene electrotransfer to progress as a treatment modality and enter clinical trials, it is of utmost importance to know the duration and level of the transgene expression.

Few studies have been conducted with the focus on duration and level of transgene expression and mostly with luciferase. ${ }^{17,23,41}$ Heller et al. ${ }^{23}$ found a peak in expression 2 days after gene electrotransfer with $100 \mu \mathrm{g}$ luciferase, but the level of expression remained substantially elevated compared to controls 2 weeks after the transfection, and data from Roos et al..$^{36}$ confirmed these results. We found a peak in expression 2 days after gene electrotransfer with luciferase, which is comparable to the results reported in the literature. Surprisingly, the peak in expression of luciferase is different than the results obtained after gene electrotransfer with Katushka and EPO, which showed a peak after 1-2 weeks, and it remains to be investigated what causes this difference.

In vivo bioimaging has the possibility of continuous monitoring, which gives a good resolution of the curve and allows for more data points without using too many animals in the process. Each animal serves as its own control, which reduces variation.

Data from two different quantitative methods are presented here: continuous in vivo bioimaging of Katushka and bioluminescence scans after gene electrotransfer with luciferase, which both define the local expression, and measurements of serum EPO, which is a proof of systemic distribution of the transgene.

From the transfection procedure to the initiation of production of protein encoded by the transgene, studies have shown less than $30 \mathrm{~min}$ elapse, ${ }^{36}$ which make our findings of an increase in expression already after $24 \mathrm{~h}$ valid.

We found a peak of expression after 9 days for Katushka and 14 days for EPO, and that the intensity in NC from the Katushka scanning was normalized after 3 weeks, whereas the serum EPO level after gene electrotransfer was nearly normalized after 4 weeks. We thus conclude from the experiments that the duration of the expression could be 3-4 weeks.

This assumption is based on the data obtained in the studies presented and hence the kinetics of the produced transgene is not taken into account. To define the exact duration of expression directly in the skin, techniques such as PCR could be of value. This would enlighten whether a measured value is in fact due to continued expression or due to remnants of the transgene. However, because the $\mathrm{T} \frac{1}{2}$ for EPO is in the range of $3-7 \mathrm{~h},{ }^{42,43}$ serum EPO measurements can be a valid alternative for determination of the duration of expression.

From the curves, we can speculate that the $\mathrm{T} \frac{1}{2}$ of Katushka is not longer than the T $\frac{1}{2}$ for EPO but further data on Katushka expression will be needed to investigate this point.

The fact that a peak in expression of transgene is achieved after 1-2 weeks and that the expression probably continues for 3-4 weeks can have an impact on the choice of issues, where gene electrotransfer to skin can be an advantage. In wound healing, small wounds could obtain a considerable improvement in 2-3 weeks and if necessary, it would be possible to re-transfect the new margin of the wound. Another issue is cancer therapy. Gene electrotransfer to skin could be an option because the 3-4 weeks duration of the expression of the transgene correlates to courses of chemotherapy; often administrated every 3 weeks.

Finally, in vaccinations against various infectious diseases, the duration of the transgene expression is prolonged compared to the standard vaccines, which are degraded after few days, and thus would work as a vaccine with sustained release.

In conclusion, we present data from continuous monitoring of a local transgenic fluorescent marker molecule, Katushka, and from a systemically secreted protein (EPO) and find these two compounds relevant supplements in estimating efficiency of gene electrotransfer to skin.

Gene electrotransfer to skin has proven to be an efficient and safe means of transfecting genes into skin, and if we want this technique to become an option in future clinical trials with DNA vaccinations and gene therapy, duration and level of expression is of utmost importance and must be defined. On the basis of the results from two different transgenes and two different means of evaluation, we conclude that a peak in expression will occur 1-2 weeks after the transfection and probably last for 3-4 weeks.

\section{Materials and methods}

\section{Animals}

Female NMRI mice 13- to 15-week-old own breed (Copenhagen University Hospital Herlev) were used in the studies presented here. Mice were kept in a pathogen-free environment in a $12 \mathrm{~h}$ light/darkness cycle with food and water ad libitum. During the experiments mice were anesthetized with Hypnorm (0.4 ml/kg; Janssen Saunderton, Buckinghamshire, UK) and Dormicum ( $2 \mathrm{mg} / \mathrm{kg}$; Roche, Basel, Switzerland) and had the hair on the right side of the back removed by depilatory cream. At termination of the studies, the animals were killed with quick cervical dislocation. All studies were performed with approval from the Danish Animal Experiments Inspectorate and in accordance with the European Convention for the Protection of Vertebrate Animals used for Experimentations.

\section{Plasmid constructs}

Luciferase, CMV-luc (Promega Corporation, Madison, WI, USA), was used in the bioluminescence studies and a new construct with emission in the far-red area, Katushka, pTurboFP635-c (Evrogen, Moscow, Russia) both controlled by a CMV promoter, was used for in vivo bioimaging. The plasmids were purified using Nucleobond AX Maxiprep kits (Macherey-Nagel, Düren, Germany) according to the manufacturer's protocol. In all transfections, the injected volume of plasmid was $100 \mu \mathrm{g}$ plasmid dissolved in $100 \mu \mathrm{l}$ PBS (final concentration $\left.1 \mu \mathrm{g} \mu \mathrm{l}^{-1}\right)$.

\section{Gene electrotransfer procedure and electrical parameters}

For each transfection, $100 \mu \mathrm{g}$ plasmid $\left(1 \mu \mathrm{g} \mu \mathrm{l}^{-1}\right)$ was carefully injected intradermally with a 29G insulin syringe and within 2 min the injected area was electroporated. We used custom-made plate electrodes with a distance of $3 \mathrm{~mm}$ between the plates connected to a Cliniporator (IGEA, Carpi, Italy) for delivery of the 
electric pulses. The electrodes were coated with electrode gel, EKO-GEL (Ekkomarine Medico, Holstebro, Denmark), to secure proper contact with the skin. The pulses consisted of one high-voltage pulse, $1000 \mathrm{~V} \mathrm{~cm}^{-1}$, $100 \mu$ s of length and one low-voltage pulse, $100 \mathrm{~V} \mathrm{~cm}^{-1}$ and duration of $400 \mathrm{~ms}$. There was a lag of $1 \mathrm{~s}$ between the pulses.

\section{Bioimaging procedure}

For in vivo bioimaging, we used an Optix MX-2 Time Domain Optical Imaging (ART Advanced Research Technologies, Montreal, Canada). The time domain function allows for accurate determination of the spatial and temporal distribution of the emitted light and thus to measure the fluorescent molecule quantitatively. Furthermore, the fluorescent lifetime, which is distinctive for each fluorochrome, can be evaluated.

Before the procedure, animals were anesthetized, placed on a platform and carefully fixated. For in vivo imaging of Katushka, a pulsing laser with a $635 \mathrm{~nm}$ wavelength was used for excitation of the tissue and emission was detected with a $650 \mathrm{~nm}$ long pass filter. The intensity was reported as peaks in normalized counts (NC) after background subtraction and fluorescent lifetime of transfected area was estimated.

In studies with mice transfected with luciferase, in vivo bioluminescence was detected using the Optix MX-2, and the intensity of luciferase expression was reported as peaks in NC as well.

For data analysis, background subtraction, and lifetime analysis Optiview 2.2 software (ART Advanced Research Technologies) was used.

\section{Duration of expression after gene electrotransfer with Katushka to skin}

Eight mice were injected intradermally with $100 \mu \mathrm{g}$ Katushka plasmid $\left(1 \mu \mathrm{g} \mu \mathrm{l}^{-1}\right)$ and were electroporated as described above. Two mice were injected with Katushka plasmid but received no electroporation and two mice had intradermal injection of PBS with subsequent electroporation. Mice were scanned 2, 4, 7, $11,14,17$ and 21 days after transfection.

\section{Kinetic study of i.p. injection of luciferin}

A study was conducted with the purpose of finding the optimal time for bioluminescence scans after i.p. injection of luciferin. Six mice were injected intradermally with $100 \mu \mathrm{g}$ luciferase plasmid $\left(1 \mu \mathrm{g} \mu \mathrm{l}^{-1}\right)$ and subsequently electroporated. After $48 \mathrm{~h}$ the animals were anesthetized and had an i.p. injection of $3 \mathrm{mg}$ luciferin (Promega Corporation) in $\mathrm{NaCl}\left(10 \mathrm{mg} \mathrm{ml}^{-1}\right)$ and each mouse was scanned for bioluminescence at different time points up to $35 \mathrm{~min}$. Controls were injection of luciferase without electroporation and intradermal injection of PBS with electroporation. An additional control was gene electrotransfer with luciferase but i.p. injection of $\mathrm{NaCl}$ before scanning instead of luciferin.

\section{Expression of luciferase over time after gene electrotransfer to skin}

To investigate the duration of luciferase gene expression, we conducted a kinetic study using in vivo detection of bioluminescence. Seven mice were injected intradermally with $100 \mu \mathrm{g}$ luciferase plasmid $\left(1 \mu \mathrm{g} \mu \mathrm{l}^{-1}\right)$ and electroporated as described above. As controls served two mice receiving luciferase plasmid injection without electric pulses, two mice receiving intradermal PBS injection with electroporation, and one mouse was a blank control. At different time points the animals were anesthetized, had the hair on the treated area removed if necessary, injected with luciferin intraperitoneally and scanned for bioluminescence. At day 17, the study was terminated and the animals were killed.

\section{Evaluation of serum EPO levels after gene electrotransfer to skin with plasmid coding for EPO} These studies are described in detail by Gothelf et al. ${ }^{33}$ The plasmid used was pUHD-EPO controlled by the doxycycline-dependent promoter system Tet-On and Tet-S, and for each EPO injection a solution of $50 \mu \mathrm{g}$ pUHD-EPO, $50 \mu \mathrm{g}$ Tet-On and $50 \mu \mathrm{g}$ Tet-S diluted in $100 \mu \mathrm{l}$ PBS (final concentration $1.5 \mu \mathrm{g} \mu \mathrm{l}^{-1}$ ) was administered.

Mice were anesthetized and had the hair on the right side of the back removed. Groups of mice were treated with (1) two i.d. injections of EPO plasmid solution and subsequent electrotroporation, (2) two i.d. injections of EPO plasmid solution alone or (3) two i.d. injections of $100 \mu \mathrm{l}$ PBS and subsequent electroporation. At different time points, mice were anesthetized and exsanguinated to measure serum EPO levels with enzyme-linked immunosorbent assay (Quantikine ELISA kit; R\&D Systems, Minneapolis, MN, USA) according to the manufacturer's protocol.

\section{Statistics}

In the study encompassing duration of expression after gene electrotransfer with Katushka, data were analyzed with Student's t-test, Katushka transfection versus Katushka injection alone and Katushka transfection versus the PBS control for each condition. In both studies involving gene transfection with luciferase, Student's $t$-test was used as well. $P$-values $<0.05$ were reported as statistically significant.

\section{Conflict of interest}

The authors declare no conflict of interest.

\section{Acknowledgements}

This work was funded by the Angioskin Project, EU 6th FP and Copenhagen Research Council. We thank Marianne Fregil and Birgit Hertz for assistance in the laboratory and for the production of plasmid. We also thank Anne Boye and Lone Christensen for excellent assistance in the animal facilities.

\section{References}

1 Heller L, Merkler K, Westover J, Cruz Y, Coppola D, Benson K et al. Evaluation of toxicity following electrically mediated interleukin-12 gene delivery in a B16 mouse melanoma model. Clin Cancer Res 2006; 12: 3177-3183.

2 Medi BM, Singh J. Skin targeted DNA vaccine delivery using electroporation in rabbits II. Safety Int J Pharm 2006; 308: 61-68. 
3 Hojman P, Gissel H, Andre F, Cournil-Henrionnet C, Eriksen J, Gehl J et al. Physiological effects of high and low voltage pulse combinations for gene electrotransfer in muscle. Hum Gene Ther 2008; 19: 1249-1260.

4 Aihara H, Miyazaki J. Gene transfer into muscle by electroporation in vivo. Nat Biotechnol 1998; 16: 867-870.

5 Mir LM, Bureau MF, Rangara R, Schwartz B, Scherman D. Long-term, high level in vivo gene expression after electric pulse-mediated gene transfer into skeletal muscle. C $R$ Acad Sci III 1998; 321: 893-899.

6 Draghia-Akli R, Ellis KM, Hill LA, Malone PB, Fiorotto ML. High-efficiency growth hormone-releasing hormone plasmid vector administration into skeletal muscle mediated by electroporation in pigs. FASEB J 2003; 17: 526-528.

7 Hojman P, Gissel H, Gehl J. Sensitive and precise regulation of haemoglobin after gene transfer of erythropoietin to muscle tissue using electroporation. Gene Ther 2007; 14: 950-959.

8 Muramatsu T, Arakawa S, Fukazawa K, Fujiwara Y, Yoshida T, Sasaki $\mathrm{R}$ et al. In vivo gene electroporation in skeletal muscle with special reference to the duration of gene expression. Int I Mol Med 2001; 7: 37-42.

9 Blair-Parks K, Weston BC, Dean DA. High-level gene transfer to the cornea using electroporation. J Gene Med 2002; 4: 92-100.

10 Dean DA, hado-Aranda D, Blair-Parks K, Yeldandi AV, Young JL. Electroporation as a method for high-level nonviral gene transfer to the lung. Gene Ther 2003; 10: 1608-1615.

11 Heller R, Jaroszeski M, Atkin A, Moradpour D, Gilbert R, Wands $\mathrm{J}$ et al. In vivo gene electroinjection and expression in rat liver. FEBS Lett 1996; 389: 225-228.

12 Suzuki T, Shin BC, Fujikura K, Matsuzaki T, Takata K. Direct gene transfer into rat liver cells by in vivo electroporation. FEBS Lett 1998; 425: 436-440.

13 Tsujie M, Isaka Y, Nakamura H, Imai E, Hori M. Electroporationmediated gene transfer that targets glomeruli. J Am Soc Nephrol 2001; 12: 949-954.

14 Iwashita H, Yoshida M, Nishi T, Otani M, Ueda S. In vivo transfer of a neuronal nitric oxide synthase expression vector into the rat bladder by electroporation. BJU Int 2004; 93: 1098-1103.

15 Widlak W, Scieglinska D, Vydra N, Malusecka E, Krawczyk Z. In vivo electroporation of the testis versus transgenic mice model in functional studies of spermatocyte-specific hst70 gene promoter: a comparative study. Mol Reprod Dev 2003; 65: 382-388.

16 Lucas ML, Jaroszeski MJ, Gilbert R, Heller R. In vivo electroporation using an exponentially enhanced pulse: a new waveform. DNA Cell Biol 2001; 20: 183-188.

17 Pavselj N, Preat V. DNA electrotransfer into the skin using a combination of one high- and one low-voltage pulse. J Control Release 2005; 106: 407-415.

18 Cemazar M, Sersa G, Wilson J, Tozer GM, Hart SL, Grosel A et al. Effective gene transfer to solid tumors using different nonviral gene delivery techniques: electroporation, liposomes, and integrin-targeted vector. Cancer Gene Ther 2002; 9: 399-406.

19 Lucas ML, Heller R. IL-12 gene therapy using an electrically mediated nonviral approach reduces metastatic growth of melanoma. DNA Cell Biol 2003; 22: 755-763.

20 Daud AI, DeConti RC, Andrews S, Urbas P, Riker AI, Sondak VK et al. Phase I trial of interleukin-12 plasmid electroporation in patients with metastatic melanoma. J Clin Oncol 2008; 26: 5896-5903.

21 Mir LM, Bureau MF, Gehl J, Rangara R, Rouy D, Caillaud JM et al. High-efficiency gene transfer into skeletal muscle mediated by electric pulses. Proc Natl Acad Sci USA 1999; 96: 4262-4267.

22 Heller LC, Heller R. In vivo electroporation for gene therapy. Hum Gene Ther 2006; 17: 890-897.

23 Heller LC, Jaroszeski MJ, Coppola D, McCray AN, Hickey J, Heller R. Optimization of cutaneous electrically mediated plasmid DNA delivery using novel electrode. Gene Therapy 2007; 14: 275-280.
24 Drabick JJ, Glasspool-Malone J, King A, Malone RW. Cutaneous transfection and immune responses to intradermal nucleic acid vaccination are significantly enhanced by in vivo electropermeabilization. Mol Ther 2001; 3: 249-255.

25 Babiuk S, Baca-Estrada ME, Foldvari M, Baizer L, Stout R, Storms $\mathrm{M}$ et al. Needle-free topical electroporation improves gene expression from plasmids administered in porcine skin. Mol Ther 2003; 8: 992-998.

26 Zhang L, Widera G, Rabussay D. Enhancement of the effectiveness of electroporation-augmented cutaneous DNA vaccination by a particulate adjuvant. Bioelectrochemistry 2004; 63: 369-373.

27 Medi BM, Hoselton S, Marepalli RB, Singh J. Skin targeted DNA vaccine delivery using electroporation in rabbits. I: efficacy. Int J Pharm 2005; 294: 53-63.

28 Hirao LA, Wu L, Khan AS, Satishchandran A, Draghia-Akli R, Weiner DB. Intradermal/subcutaneous immunization by electroporation improves plasmid vaccine delivery and potency in pigs and rhesus macaques. Vaccine 2008; 26: 440-448.

29 Dobano C, Widera G, Rabussay D, Doolan DL. Enhancement of antibody and cellular immune responses to malaria DNA vaccines by in vivo electroporation. Vaccine 2007; 25: 6635-6645.

30 Hooper JW, Golden JW, Ferro AM, King AD. Smallpox DNA vaccine delivered by novel skin electroporation device protects mice against intranasal poxvirus challenge. Vaccine 2007; 25: 1814-1823.

31 Roos AK, Moreno S, Leder C, Pavlenko M, King A, Pisa P. Enhancement of cellular immune response to a prostate cancer DNA vaccine by intradermal electroporation. Mol Ther 2006; 13: 320-327.

32 Roos AK, Eriksson F, Walters DC, Pisa P, King AD. Optimization of skin electroporation in mice to increase tolerability of DNA vaccine delivery to patients. Mol Ther 2009; 17: 1637-1642.

33 Gothelf A, Hojman P, Gehl J. Therapeutic levels of erythropoietin (EPO) achieved after gene electrotransfer to skin in mice. Gene Ther. Accepted for publication 2010.

34 Byrnes CK, Malone RW, Akhter N, Nass PH, Wetterwald A, Cecchini MG et al. Electroporation enhances transfection efficiency in murine cutaneous wounds. Wound Repair Regen 2004; 12: 397-403.

35 Heller LC, Jaroszeski MJ, Coppola D, Heller R. Comparison of electrically mediated and liposome-complexed plasmid DNA delivery to the skin. Genet Vaccines Ther 2008; 6: 16.

36 Roos AK, Eriksson F, Timmons JA, Gerhardt J, Nyman U, Gudmundsdotter $\mathrm{L}$ et al. Skin electroporation: effects on transgene expression, DNA persistence and local tissue environment. PLoS ONE 2009; 4: e7226.

37 Gareau DS, Bargo PR, Horton WA, Jacques SL. Confocal fluorescence spectroscopy of subcutaneous cartilage expressing green fluorescent protein versus cutaneous collagen autofluorescence. J Biomed Opt 2004; 9: 254-258.

38 Shcherbo D, Merzlyak EM, Chepurnykh TV, Fradkov AF, Ermakova GV, Solovieva EA et al. Bright far-red fluorescent protein for whole-body imaging. Nat Methods 2007; 4: 741-746.

39 Hojman P, Eriksen J, Gehl J. In vivo imaging of far-red fluorescent proteins after DNA electrotransfer to muscle tissue. Biol Proced Online 2009 [Epub ahead of print 10 April 2009].

40 Ferraro B, Cruz YL, Coppola D, Heller R. Intradermal delivery of plasmid VEGF(165) by electroporation promotes wound healing. Mol Ther 2009; 17: 651-657.

41 Zhang L, Nolan E, Kreitschitz S, Rabussay DP. Enhanced delivery of naked DNA to the skin by non-invasive in vivo electroporation. Biochim Biophys Acta 2002; 1572: 1-9.

42 Lezon CE, Martinez MP, Conti MI, Bozzini CE. Plasma disappearance of exogenous erythropoietin in mice under different experimental conditions. Endocrine 1998; 8: 331-333.

43 Bugelski PJ, Nesspor T, Volk A, O'Brien J, Makropoulos D, Shamberger $\mathrm{K}$ et al. Pharmacodynamics of recombinant human erythropoietin in murine bone marrow. Pharm Res 2008; 25: 369-378. 